\title{
A ATUALIDADE DA PROPOSTA PEDAGÓGICA DE CÉLESTIN FREINET
}

\author{
LA ACTUALIDAD DE LA PROPUESTA EDUCATIVA DE CÉLESTIN \\ FREINET
}
THE ACTUALITY OF THE PEDAGOGICAL PROPOSAL OF CÉLESTIN FREINET

Marisa Del Cioppo ELIAS ${ }^{1}$

RESUMO: O objetivo deste artigo é mostrar que a Pedagogia Freinet pode auxiliar o professor na educação das crianças e jovens da atualidade. Mostrar que o uso das técnicas criadas por Célestin Freinet, no século passado, década de 1920, permitem um trabalho pedagógico de sucesso na sala de aula, uma vez que estão consubstanciadas em conquistas tecnológicas e sociais contemporâneas.

PALAVRAS-CHAVE: Célestin Freinet. Proposta Pedagógica. Educação.

RESUMEN: El propósito de este artículo es mostrar que la pedagogía Freinet puede ayudar al maestro en la educación de los niños y jóvenes de hoy en día. Muestran que el uso de las técnicas desarrolladas por Célestin Freinet en el siglo pasado, los años 1920, permite un éxito trabajo de enseñanza en el aula, ya que están incorporados en los logros tecnológicos y sociales contemporáneos.

PALAVRAS CLAVE: Célestin Freinet. Propuesta pedagógica. Educación.

SUMMARY: The aim of this article is to show that the Freinet Pedagogy can help the teacher in the education of children and young people of today. Show that the use of the techniques created by Célestin Freinet, in the last century, in the 1920's, allow a pedagogical work for success in the classroom, since they are substantiated by contemporary social and technological achievements.

KEYWORDS: Célestin Freinet. Pedagogical Proposal. Education

${ }^{1}$ Profa. Doutora. PUC-SP. E-mail: marisadelcioppoelias@gmail.com. 


\section{Introdução}

Uma das vantagens de ter vivido um bocado de anos é poder lembrar eventos significativos do passado e que permitem entender os que estão por vir. Lembro, por exemplo, quando em 1988, chegando à PUC-SP para trabalhar me deparei com um convite: participar da XVII RIDEF² que aconteceria em Florianópolis, Santa Catarina, Brasil. Até então pouco conhecia da Pedagogia Freinet. Procurei me informar mais ${ }^{3}$ e viajei para participar do Encontro onde conheci pessoas maravilhosas e pude vivenciar um pouco de uma pedagogia da qual não mais me separaria.

De lá para cá tenho procurado participar e aprofundar estudos sobre o trabalho pedagógico de um educador, como nós, idealista e batalhador, que acreditava numa educação diferente da que existe, numa educação como meio de transformação, como forma de descoberta da ARTE DE VIVER; acreditava na possibilidade de construir o conhecimento em vez de transmiti-lo, de fazer da escola um espaço de debate, discussão e reflexão em vez de implantar dogmas.

Estamos nos deparando, neste início de século, com um dilema crucial: como educar as crianças e jovens para uma sociedade futura cuja natureza desconhecemos em detalhes, mas que certamente será diferente, em muitos aspectos fundamentais, do passado e do presente? Se concordamos que a concepção de educação "como direito abarca as intencionalidades do processo educacional, em direção à garantia de acesso, pelos estudantes e pelas estudantes, às condições para seu exercício de cidadania"4, preparando-os para o seu futuro (e não para o nosso passado), então uma visão através do para-brisa será mais útil do que aquela vista pelo espelho retrovisor.

Freinet se antecipou no tempo ao usar, já no século passado, na década de 20, técnicas que hoje ainda não foram devidamente exploradas, em sua total dimensão, nem pela escola, nem pelos educadores, nem pelos meios acadêmicos. Construídas a partir de suas investigações e de seu imaginário, num trabalho de globalização de cunho político, têm levado seus seguidores a utilizá-las com sucesso em sala de aula, hoje consubstanciadas com as conquistas tecnológicas e sociais contemporâneas.

O fato de ter trabalhado como professor de escola elementar e ter tropeçado em todos os obstáculos de uma prática escolar difícil, que exige muito trabalho, não

\footnotetext{
${ }^{2}$ Rencontre Internationale des educateurs Freinet.

${ }^{3}$ Conheci Rosa Maria W. F. Sampaio que na ocasião muito me auxiliou.

${ }^{4}$ BRASIL, Ministério da Educação. Base Nacional Comum Curricular, proposta preliminar, $2^{\mathrm{a}}$ versão, abril, 2016, p. 24
} 
impediu Freinet de edificar uma escola prazerosa, onde o coração, a afetividade e as emoções predominassem, onde houvesse alegria e prazer para descobrir e aprender. Seus escritos são o registro vivo do trabalho e das pesquisas que desenvolveu e documentam uma concepção antropológica de educação bastante inovadora. Seu fundamento é a vivencia histórico-social situada e o pensar interdisciplinar que valorizava o homem, o coletivo, o homem da periferia e das classes trabalhadoras, e via no erro novas possibilidades para a aprendizagem.

Fica claro para nós que, para que "todos os brasileiros e todas as brasileiras tenham acesso a conhecimentos e a condição de aprendizagem e desenvolvimento que lhes assegurem o pleno exercício da cidadania”, como propõe a $\mathrm{BNCC}^{5}$ é necessário reavaliar aquilo que estamos fazendo em educação. Por outro lado, é conveniente lembrar que a sociedade contemporânea está passando por uma série de modificações estruturais que nos obrigam a tal reavaliação. Freinet aponta para uma concepção original para trabalhar os direitos e os objetivos de aprendizagem e desenvolvimento dos educandos, relacionados às suas experiências culturais.

A educação, compreendida como direito humano, individual e coletivo nunca foi descuidada por Freinet, que pode ser considerado o primeiro educador a fixar as bases para o desenvolvimento de uma psicologia da ação. Para transformar uma situação social que não aprovava e, para definir os direitos fundamentais à aprendizagem para as crianças e os jovens, e suas possibilidades, a tudo recorre, procurando fazer da escola um centro de atividades. Buscava, para seus alunos, uma formação integral, e almejava a construção de uma sociedade mais justa, na qual todas as formas de discriminação, preconceito e exclusão fossem combatidas.

As novas técnicas - a Pedagogia do Bom Senso - possibilitam ao professor rever a própria postura em relação ao ensino e à educação, abrindo todos os caminhos possíveis em prol da efetivação da educação como direito social, com qualidade, para todos. Nenhum professor praticante da Pedagogia Freinet partiu, de início, de uma classe bem equipada. Todos tiveram que desbravar caminhos para poder respeitar o novo processo e, logicamente, opor-se a tudo que condenavam. Tiveram que enfrentar diretores, inspetores e colegas que os olhavam como se fossem uns loucos e, pais, que nem sequer imaginavam que a escola pudesse ser criticada e melhorada, e que desconfiavam das mudanças metodológicas propostas. No âmbito de suas escolas e, por

${ }^{5}$ Idem, ibidem. 
meio da correspondência e apoio de colegas foram modificando as estratégias didáticas e metodológicas usadas anteriormente e reforçando as mediações pedagógicas, a partir dos estudos da proposta freinetiana e das características e necessidades cognitivas dos seus educandos.

Se a mudança na sociedade atual é veloz, como preparar nossas crianças e jovens para um mundo de valores e de trabalho diferentes dos atuais? Freinet de novo nos ajuda com sua observação de que, a criança deve ser levada a buscar referenciais teóricos e práticos para solucionar problemas de conteúdos programáticos presentes no currículo das escolas, através de uma aprendizagem pela disciplina do trabalho.

O educando deve ser preparado para o seu papel de homem e de trabalhador ativo. Daí ser levado a pesquisar e montar concretamente suas experiências e descobrir; ser criador e elaborador do próprio conhecimento que depois será trocado com os colegas.

Todos somos pesquisadores; pesquisar é um processo instintivo através do qual o homem busca o próprio conhecimento; tateia porque quer caminhar em direção a um objetivo que serve à vida. Não são as conquistas que impulsionam o homem para a frente? Escreveu Freinet, em sua $7^{\mathrm{a}}$ Lei do Comportamento (apud FREINET, 1979, p. 123): "uma experiência vitoriosa enquanto se pesquisa cria como que um apelo de poder e tende a se reproduzir mecanicamente para transformar-se em regra de vida”. Tal transformação só acontece como um ato inteligente, isto é, para Freinet a pesquisa, que antes, era mecânica, torna-se inteligente ao inscrever-se no processo funcional do indivíduo (permeabilidade à experiência).

Parece uma constatação simplista; no entanto, nos leva à definição dos direitos éticos, políticos e estéticos fundamentais à aprendizagem e ao desenvolvimento com os quais o trabalho que se realiza na escola deve se comprometer.

Freinet de novo nos ajuda com sua observação de que, enquanto no passado a metáfora que explicava como funciona a aprendizagem foi o ato de vigiar " $a$ subida metódica da escada, degrau por degrau" ", isto é, realizar pequenos passos cumulativos levando até um patamar onde o conhecimento, frente à complexidade e 'velocidade das mudanças se estabelecesse cientificamente, adaptado às possibilidades e necessidades das pernas dos educandos.

${ }^{6}$ In FREINET, C. Pedagogia do Bom Senso, São Paulo: Martins Fontes Editoras, 1985, p.9 
Acreditamos que o objetivo, a meta principal, de toda a educação, hoje, tem que ser o de preparar o futuro adulto para pensar sistêmica e ecologicamente, apropriando-se de conhecimentos referentes à área socioambiental que afetam a vida e a dignidade humanas. A nova meta da educação tem que ser não o que pensar mas, sim, como pensar. Oportunidade de se formar indivíduos bem informados, capazes de exercitar o diálogo, respeitar o outro, saber reivindicar e solucionar conflitos, sem deixar de se apropriar dos conhecimentos e experiências historicamente constituídos.

Ao identificar formas de pensar "holísticas" Freinet (1985, p. 74) exemplifica: " $a$ ciência constrói robôs que, com dois mais dois, calculam a uma velocidade vertiginosa e que são capazes de baixar as alavancas do comando e de levar a morte para além das ondas. Não realizou ainda, infelizmente! o homem que pensa, mas com fios e engrenagens, mas com o seu ser sensivel e capaz de marcar, com o próprio cunho, o destino dos robôs. É esse ser sensível que temos de educar, não somente para criar e animar robôs, mas também para dominá-los e os sujeitar, a fim de exaltar os elementos de consciência e de humanidade que são a grandeza e a razão de ser do homem".

Uma visão holística significa ver o mundo como um todo, integrado, e não como uma coleção dissociada de partes e, uma visão ecológica, além de incluir isso adiciona o reconhecimento da fundamental interdependência de todos os fenômenos e o fato de que, como indivíduos e sociedade, estamos inseridos e, em última análise, dependentes de processos cíclicos da natureza; de onde vieram os materiais usados na fabricação dos robôs, como foram construídos, como o seu uso afeta o meio ambiente natural e a comunidade.

Freinet observa que novas formas de pensar estão intimamente ligadas aos valores, à ética e a estética, e que é urgente preparar novas gerações para um equilíbrio entre formas antigas (porém ainda úteis) de pensar e formas novas. Fica claro que indivíduos que estão sendo preparados para sobreviver no futuro deverão usufruir dos direitos à participação em práticas e funções de bens culturais diversificados, reconhecendo-os como parte da cultura universal e local.

Ao propor uma metodologia da ação e do trabalho, a bem dizer, uma Pedagogia Experimental, Freinet estava definindo uma concepção sistêmica, que leva a tomada de decisões, as trocas em termos de conexões, relações, contextos, interações entre os elementos de um todo, de ver coisas em termos de redes, teias e comunidades. Para levar o aluno a pensar sistemicamente foi que dedicou o melhor do seu tempo, reinventando e inventando técnicas e atividades nunca antes trabalhadas. Assim, para 
fazer aparecer dados intelectuais de uma teoria que brotasse da ação, nunca descuidou ou separou a educação da vida, nunca isolou a escola dos fatos sociais e políticos que a determinavam e condicionavam.

Se a nossa meta é o pensamento ecológico e sistêmico, quais são os meios para levar o professor e o aluno até ela? São as capacidades e habilidades que, como o pensamento ecológico e sistêmico, sabemos que podem ser transferidas para qualquer profissão, qualquer área de trabalho, em qualquer parte do mundo. Essas habilidades devem fazer parte do currículo das escolas propostos pela Base Nacional Comum Curricular (BNCC) e que devem ser propostas nos Projetos Políticos Pedagógicos (PPPs) das Unidades Escolares (UEs) para serem aprendidas.

É a qualidade social da educação brasileira, celebrada nas Diretrizes Curriculares Nacionais da Educação Básica(DCNEB) que "deve ser construída de forma negociada, pois significa algo que se concretiza a partir da qualidade da relação entre todos os sujeitos que nela atuam direta ou indiretamente. Significa compreender que a educação é um processo de socialização da cultura da vida, no qual se constroem, se mantem e se transformam conhecimentos e valores" (2013, p.20).

O trabalho pedagógico de Freinet, embora de grande valor para a prática, principalmente para um melhor entendimento das questões do ensinar e do aprender, tem sido pouco divulgado e pouco explorado pelas escolas e professores da atualidade, os mesmos que criticam as práticas pedagógicas tradicionais mecanicistas. Priorizando o trabalho como meio, e a busca do conhecimento integral e interdisciplinar como fim, Freinet antevia a interdisciplinaridade como uma exigência natural e interna, da qual se utilizava para melhor compreender a realidade dos educandos e para poder relacionar os conhecimentos que traziam. As trocas e a cooperação mútua chegaram até nós como pilares da construção de uma escola viva, a escola moderna.

Portanto, para Freinet, a solução da questão metodológica já era vista como de exclusiva responsabilidade do professor que, com suficiente intuição e sensibilidade, com equilíbrio, domínio e autoridade, pode, até sem preparação especial, sem técnica e sem material, conseguir resultados bastante satisfatórios. Basta que tenha um compromisso com a totalidade. Essa compreensão da realidade, na busca de um fazer interdisciplinar e ecológico, foi também a marca de sua trajetória pedagógica, facilitando a abertura e reciprocidade para a comunicação, as trocas, a cooperação e o diálogo com colegas. 
Os direitos à aprendizagem e ao desenvolvimento são hoje revividos pelos educandos e professores das escolas Freinet, através do exercício da correspondência. Este orienta, estimula e facilita a aquisição dos conhecimentos. A intervenção, neste caso, se limita a dar a palavra ao educando e proporcionar os meios para que possa manifestar-se de forma consciente. Assim, o trabalho colabora para o desenvolvimento integral do sujeito, com vistas a atender à meta de inclusão plena e proporcionar os meios para construir o próprio conhecimento.

Como Freinet, não vemos como dar receitas ou modelos; a realidade nos desafia a cada momento e devemos responder a esses desafios de forma original, se quisermos modificá-la. Não há dúvida, também, de que o trabalho escolar, no futuro, será feito em grupo ou oficinas com indivíduos diferentes se juntando a outros com características complementares, de forma a levar a sério a questão da mediação docente.

A formação dos professores daqui em diante precisa incluir técnicas de preparação de alunos para cooperação, sendo o "trabalho em grupo" uma estratégia a ser priorizada na sala de aula. A organização para o funcionamento da classe através das oficinas expõe o grupo-classe a uma nova visão da disciplina (leva o aluno a estabelecer um conjunto de relações sociais que atuam sobre suas concepções de homem, mundo e sociedade). Seu objetivo fundamental é a realização de um trabalho real e socialmente produtivo, centro de toda atividade escolar. A organização cooperativa da classe facilita o trabalho e a interação na sala de aula.

A elaboração e o desenvolvimento do conhecimento estão ligados ao processo de conscientização que condiciona pensamento e ação. Portanto, ao educador cabe fornecer condições de trabalho e ação, aproximar o educando da realidade para que este possa desvendá-la e criticá-la, para poder reconstruí-la e reinventá-la, transformando, assim, a simples esfera da apreensão.

Freinet consagrou 46 anos de sua vida (neste ano estamos comemorando 50 anos de seu falecimento) à atividade pedagógica, dedicando os últimos 15 anos ao aperfeiçoamento de sua pedagogia, criando, ainda que com grandes dificuldades, um belo coletivo de educandos e educadores que hoje continuam o seu trabalho.

Precisamos formar professores críticos e conscientes que borbulhem desejo de mudanças, pessoas atentas ao mundo e inseridas em seu tempo. Estamos juntos porque não desistimos da luta de fazer da educação prazer e renovação; e de fazer da escola o espaço de encontros, descobertas e buscas. 


\section{Referências}

BARRÉ, Michel. Céletin Freinet - un éducateur pour notre temps. France, PEMF Mouans - Sartoux, 1995.

BRASIL. Ministério da Educação. Secretaria da Educação Básica. Secretaria da Educação Continuada. Diretrizes Curriculares Nacionais Gerias da Educação Básica. Brasilia: MEC, SEB, DICEI, 2013.

ELIAS, Marisa D.C. Célestin Freinet: uma pedagogia da atividade e cooperação. 9.ed. Petrópolis, RJ: Vozes, 2010.

ELIAS, Marisa D.C. De Emílio a Emília: a trajetória da alfabetização. São Paulo: Scipione, 2000.

ELIAS, Marisa D.C. Pedagogia Freinet: teoria e prática. Campinas-SP: Editora Papirus, 1996.

FREINET, Célestin. A educação do trabalho. São Paulo: Martins Fontes, 1998.

FREINET, Célestin. Pedagogia do Bom Senso. São Paulo: Martins Fontes, 1985.

FREINET, Elise. O itinerário de Célestin Freinet: a livre expressão da Pedagogia Freinet. Rio de Janeiro: Livraria Francisco Alves, 1979.

Como referenciar este artigo

ELIAS, Marisa Del Cioppo. A atualidade da proposta pedagógica de Célestin Freinet. Revista Ibero-Americana de Estudos em Educação, Araraquara, v. 12, n. esp. 1, p.612-619, 2017.2 Disponível em: <http://dx.doi.org/10.21723/riaee.v12.n.esp.1.2017.9666>. E-ISSN: 1982-5587.

Submetido em: 20/03/2017

Aprovado em: 30/03/2017 